\title{
Poor breakfast habits in adolescence predict the metabolic syndrome in adulthood
}

\author{
Maria Wennberg*, Per E Gustafsson, Patrik Wennberg and Anne Hammarström \\ Department of Public Health and Clinical Medicine, Family Medicine, Umeå University, 90187 Umeå, Sweden
}

Submitted 22 May 2013: Final revision received 21 0ctober 2013: Accepted 8 November 2013: First published online 28 January 2014

\begin{abstract}
Objective: To analyse whether poor breakfast habits in adolescence predict the metabolic syndrome and its components in adulthood. Previous studies suggest that regular breakfast consumption improves metabolic parameters.

Design: Prospective. Breakfast habits and other lifestyle variables at age 16 years were assessed from questionnaires. Poor breakfast habits were defined as skipping breakfast or only drinking or eating something sweet. At age 43 years, the effective sample consisted of 889 participants defined as having the metabolic syndrome or not, using the International Diabetes Federation criteria. Logistic regression was used to calculate odds ratios and confidence intervals.

Setting: The Northern Swedish Cohort, a longitudinal population-based cohort with 27-year follow-up.

Subjects: Adolescents (age 16 years).

Results: Prevalence of the metabolic syndrome at age 43 years was $27 \cdot 0 \%$. Of the participants, 9.9\% were classified with poor breakfast habits at age 16 years. Adjusted odds for the metabolic syndrome at age 43 years was OR $=1.68$ (95\% CI $1 \cdot 01,2 \cdot 78$ ) for those with poor breakfast habits at age 16 years compared with breakfast eaters. Looking at the metabolic syndrome components, poor breakfast habits at age 16 years were associated with central obesity $(\mathrm{OR}=1.71 ; 95 \% \mathrm{CI}$ $1 \cdot 00,2 \cdot 92)$ and high fasting glucose $(\mathrm{OR}=1 \cdot 75 ; 95 \% \mathrm{CI} 1 \cdot 01,3 \cdot 02)$ at age 43 years, even after multivariate adjustments.

Conclusions: Poor breakfast habits in adolescence predicted the metabolic syndrome in adulthood. Of the metabolic syndrome components, poor breakfast habits in adolescence predicted central obesity and high fasting glucose in adulthood. Further research is needed to fully understand the relationship between early breakfast habits and adult metabolic syndrome.
\end{abstract}

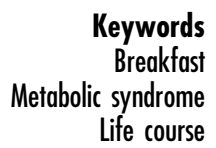

The metabolic syndrome is a cluster of risk factors central obesity, dyslipidaemia, hypertension and impaired glucose regulation - associated with increased risk of cardiometabolic diseases and early death ${ }^{(1)}$. Prevalence of the metabolic syndrome is increasing worldwide ${ }^{(2)}$. To identify factors that can be used as targets for preventing development of the metabolic syndrome is therefore of great relevance. Whereas unhealthy dietary habits in adulthood, such as low intakes of fruits and vegetables ${ }^{(3)}$, dairy $^{(4)}$ and wholegrain ${ }^{(5)}$ products and high intakes of soft drinks ${ }^{(6)}$, meat and fried foods ${ }^{(7)}$, have been implicated as a risk factor for the metabolic syndrome, few studies have investigated associations between diet in adolescence and metabolic risk later in life.

Previous studies suggest that regular breakfast consumption improves several metabolic parameters and total diet quality ${ }^{(8)}$. It has been suggested that eating in the morning is more satiating and may thus reduce total energy intake over the day ${ }^{(9)}$. Skipping breakfast has been associated with a higher BMI and weight gain in several previous studies ${ }^{(10-12)}$. In a randomized crossover trial including ten lean women, total energy intake was higher during the two-week breakfast-skipping phase than in the two weeks with breakfast ${ }^{(13)}$. The women also had higher fasting total cholesterol and LDL-cholesterol and higher postprandial insulin at the end of the breakfast-skipping phase. Regular breakfast consumption, compared with skipping breakfast or eating breakfast irregularly, has been shown to be prospectively associated with lower risk of $\mathrm{CHD}^{(14)}$, type 2 diabetes $^{(15,16)}$ and a spectrum of metabolic conditions in adults ${ }^{(17)}$.

In the USA and Europe, about $10-30 \%$ of children and adolescents regularly skip breakfast and the practice increases from childhood to adulthood ${ }^{(18)}$. In a recent cross-sectional survey conducted on 13-15-year-olds in northern Sweden, $15 \%$ of the boys and $20 \%$ of the girls reported skipping breakfast at least four days per week ${ }^{(19)}$. 
The definition of a healthy breakfast is not self-evident and different definitions of breakfast consumption have been used in previous studies ${ }^{(18)}$. In an experimental study by Pereira et al. comparing different breakfasts, it was found that a breakfast with high glycaemic index resulted in similar blood glucose levels after $5 \mathrm{~h}$ as a breakfast only consisting of water (that is, hypoglycaemia). This was suggested to be an effect of hyperinsulinaemia produced by the high-glycaemic-load condition ${ }^{(20)}$. Only drinking or eating something sweet for breakfast may thus, from a metabolic health perspective, be considered as poor breakfast habits. Evidently, skipping breakfast may also be considered as poor breakfast habits.

Previous results suggest that skipping breakfast as early as in adolescence may cause enduring health risk into adulthood. In a longitudinal study of Australian 9-15-year-olds followed up concerning cardiometabolic health over 20 years, participants who skipped breakfast in both childhood and adulthood had a larger waist circumference and higher fasting insulin, total cholesterol and LDL-cholesterol than those who reported eating breakfast at both times, after adjustments for age, sex, sociodemographic and lifestyle factors. However, the participation rate was low and the attrition rate was high (67.5\% of the invited children participated at baseline and of these about $33 \%$ participated at follow-up) ${ }^{(21)}$. To our knowledge there are no other prospective studies on breakfast habits in adolescence and the metabolic syndrome in adulthood and there is a need for such longitudinal studies with low attrition rate.

The objective of our study was to analyse whether poor breakfast habits in adolescence predict the metabolic syndrome and its components in adulthood.

\section{Methods}

\section{Selection of participants}

Participants were drawn from the Northern Swedish Cohort, a 27-year prospective cohort study, described in detail by Hammarström and Janlert ${ }^{(22)}$. All school-leavers of the 9th (final) grade (age 16 years) of the Swedish compulsory school in the municipality of Luleå in 1981 ( $n$ 1083) were invited to fill out an extensive questionnaire concerning lifestyle, health and socio-economic conditions. The cohort has been found to be representative of the corresponding age cohort of Sweden in demographic comparisons ${ }^{(22)}$. Follow-up data collections were conducted in 1983 (age 18 years), 1986 (age 21 years), 1995 (age 30 years) and 2008 (age 43 years).

Health examinations were performed at ages 16, 21 and 43 years. At the follow-up at age 43 years a more extensive health examination was performed by trained medical personnel at the participants' respective health care centre $^{(23)}$, making it possible to classify the prevalence of the metabolic syndrome. Participation in the follow-up was high; in 2008, 94\% of the baseline individuals still alive participated $(n 1003)^{(23)}$. The present report was based on data from the age 16 and age 43 years data collections. At age 16 years, questionnaires were completed in school, and at age 43 years, in conjunction with a class reunion. For those not participating in the class reunion, questionnaires were sent and returned by mail. Participants with information on breakfast habits at age 16 years and metabolic syndrome at age 43 years ( $n 889$ ) were included in the present report.

To examine potential selection bias, those excluded because of incomplete measures on either breakfast habits ( $n$ 5) or the metabolic syndrome ( $n$ 107) were compared with those included in the study. There were no statistically significant differences in breakfast habits (proportion with poor breakfast habits) or covariates included in the multivariate analyses.

\section{Poor breakfast habits at age 16 years}

Breakfast habits were elicited in the questionnaire at age 16 years ('What did you have for breakfast this morning?'). A number of food items divided into seven different food groups normally eaten for breakfast were suggested (drinks, milk products, egg/meat/fish, fruit/ vegetables, porridge/cereals, dark bread, white/sweet bread) and participants were instructed to underline what they had eaten the same morning. The alternative 'something else' accounted for food items that could have been missed. Those reporting not eating anything at all for breakfast were defined as breakfast skippers ( $n$ 66), and those reporting only drinking something energycontaining ( $n$ 12) or only eating something sweet ( $n$ 10), such as a bun, cookie or biscuit, were treated as a separate category ('drink or sweet for breakfast'; $n$ 22). Due to low frequencies in these sub-categories, both representing poor breakfast habits, these categories were collapsed into a larger 'poor breakfast habits' category in the main analysis ( $n$ 88).

\section{The metabolic syndrome and its components at age 43 years}

Waist circumference was measured to the nearest $0.5 \mathrm{~cm}$ in indoor clothing. Blood samples were collected and assessed for TAG, HDL-cholesterol and glucose according to the laboratory routines at the Department of Clinical Chemistry, Umeå University. The CV at high/low concentration was $1 \cdot 7 \% / 1 \cdot 5 \%$ for TAG, $2 \cdot 8 \% / 2 \cdot 8 \%$ for HDL-cholesterol and $1 \cdot 5 \% / 1 \cdot 2 \%$ for glucose. External quality control was managed by EQUALIS (External Quality Assurance in Laboratory medicine In Sweden). Blood pressure was measured with a standard sphygmomanometer on the participant's right arm in sitting position after resting for at least $5 \mathrm{~min}$. The mean of two measures was used.

Presence of the metabolic syndrome and its components were operationalized similarly to our previous reports ${ }^{(23,24)}$. 
According to the International Diabetes Federation definition $^{(25)}$, for a person to be defined as having the metabolic syndrome they must have central obesity (defined as waist circumference $\geq 80 \mathrm{~cm}$ for women and $\geq 94 \mathrm{~cm}$ for men), plus two or more of the following four components: (i) increased TAG ( $\geq 1.7 \mathrm{mmol} / \mathrm{l}$ ) or specific treatment for that lipid abnormality; (ii) reduced HDLcholesterol $(<1.29 \mathrm{mmol} / 1$ for women $/<1.03 \mathrm{mmol} / \mathrm{l}$ for men) or specific treatment for that lipid abnormality; (iii) increased blood pressure (systolic blood pressure $\geq 130 \mathrm{mmHg}$ or diastolic blood pressure $\geq 85 \mathrm{mmHg}$ ) or treatment of hypertension; and (iv) increased fasting glucose $(\geq 5.6 \mathrm{mmol} / \mathrm{l})$ or diagnosed type 2 diabetes. Information on medication was self-reported. Current type 2 diabetes was based on self-reported diabetes at age 43 years, excluding those who also reported diabetes at age 30 years, who were regarded as having type 1 diabetes.

Both the metabolic syndrome and its components were used as binary outcomes ( $1=$ presence, $0=$ absence $)$ in the analyses.

\section{Assessment of confounders}

Family history of diabetes was defined as a parent or sibling with diabetes, and the information was assessed from the questionnaire at age 16 years. Socio-economic status (SES) in adolescence was operationalized as in previous reports ${ }^{(23,26)}$. SES was defined by parents' occupation when the participant was aged 16 years (both parents as manual workers counted as low SES). Height and weight from school health records were used to calculate BMI $\left(\mathrm{kg} / \mathrm{m}^{2}\right)$. Daily consumption of pure alcohol was estimated from a validated battery of questions (frequency and amount of medium-strength beer, strong beer, wine and spirits). Participants above the 80th percentile (sex-specific) of alcohol consumption were classified as high consumers. Smoking habits were classified as current smoker or not (including ex-smokers). A reliability test-retest of the alcohol and tobacco questions was conducted in 1981, within a 2-month period, showing that similar answers were given by the same pupils to the same questions ${ }^{(27-29)}$. Those who reported participation in physical activity more often than once weekly were classified as physically active. Daily consumption of sweets and pastries was defined as high consumption of these food groups.

\section{Statistics}

Participants who were classified as having poor breakfast habits were compared with breakfast eaters regarding variables at baseline (age 16 years) and components of the metabolic syndrome at age 43 years, using the $\chi^{2}$ test or the non-parametric Mann-Whitney $U$ test. Crude and adjusted odds ratios for metabolic syndrome at age 43 years were calculated for those with poor breakfast habits compared with breakfast eaters at age 16 years, using binary logistic regression. Additional analyses were conducted on the sub-categories 'skipping breakfast' ( $n$ 66) and 'drink or sweet for breakfast' ( $n$ 22). The crude odds for the metabolic syndrome at age 43 years for those skipping breakfast compared with eating breakfast at age 16 years was $\mathrm{OR}=2 \cdot 18(95 \%$ CI $1.30,3.66)$ and the corresponding odds for those only drinking or eating something sweet for breakfast was $\mathrm{OR}=2 \cdot 47(95 \% \mathrm{CI}$ $1 \cdot 05,5 \cdot 81)$. The sub-categories were too small to draw conclusions, but the similar point estimates justifies combining these sub-categories to the category 'poor breakfast habits'.

In the multivariate analysis on the association between poor breakfast at age 16 years and the metabolic syndrome at age 43 years we added sex as covariate in model 1 . In model 2 we added family history of diabetes, alcohol consumption, smoking status and physical activity at age 16 years beyond covariates in model 1 . In model 3 we added BMI and parents' SES at age 16 years beyond covariates in model 2 . Sex was added because the prevalence of the metabolic syndrome is higher in men than women. The covariates added in model 2 were chosen because they were differing significantly $(P<0 \cdot 05)$ between breakfast groups and they also tended to relate to the metabolic syndrome in univariate analyses $(P<0 \cdot 25)$. The covariates added in model 3 were chosen to (as far as possible) rule out any effect of pre-existing metabolic or social risk factors. The same models were used in logistic regression analysis on separate components of the metabolic syndrome (Table 3). Our main aim was to analyse if poor breakfast habits at age 16 years predicted the metabolic syndrome and its components at age 43 years. In our predictor concept, a predictor precedes the outcome. A predictor is a variable which foretells the future risk in a population. It is important to recognize that a predictor provides no information about causality.

As an attempt to find out more about possible mediating mechanisms in the association between poor breakfast in adolescence and future risk of the metabolic syndrome, an additional multivariate analysis constituting model 3 plus lifestyle at age 43 years (consumption of fruits and vegetables and physical activity) was performed.

The statistical computations were carried out using the statistical software package IBM SPSS Statistics for Windows version 20 .

\section{Missing data}

There were a few missing data on covariates at age 16 years; at most six individuals lacked information on alcohol intake $(0 \cdot 7 \%)$. Missing data were not replaced. In the most extensive multivariate model (model 3), seventeen individuals dropped out of the analysis because of missing data on any of the covariates. We compared prevalence of poor breakfast habits and the metabolic syndrome in individuals with any missing data on covariates and individuals with complete data using a 
$\chi^{2}$ test. Individuals with any missing data on covariates did not differ significantly from those with complete data regarding breakfast habits at age 16 years $(P=0 \cdot 232)$ or prevalence of the metabolic syndrome at age 43 years $(P=0 \cdot 787)$.

\section{Etbical approval and informed consent}

The study was conducted according to the guidelines laid down in the Declaration of Helsinki and all procedures involving human subjects were approved by the Regional Ethical Review Board in Umeå. All participants gave their informed consent.

\section{Results}

The prevalence of the metabolic syndrome at age 43 years among the 889 participants was $27 \cdot 0 \%(34 \cdot 1 \%$ in men and $19 \cdot 3 \%$ in women), according to the International
Diabetes Federation definition. Of the 889 participants, eighty-eight individuals $(9.9 \%)$ were classified with poor breakfast habits. Of those classified with poor breakfast habits, sixty-six individuals were breakfast skippers and twenty-two individuals reported only drinking or eating something sweet for breakfast. As presented in Table 1, individuals who reported poor breakfast habits at age 16 years had a higher prevalence of family history of diabetes, higher alcohol consumption, a higher prevalence of smoking and a lower physical activity level compared with breakfast eaters. For components of the metabolic syndrome at age 43 years, those with poor breakfast habits at age 16 years had higher prevalence of central obesity, high TAG levels, high blood pressure and high fasting glucose (Table 1).

Poor breakfast habits at age 16 years were associated with higher odds of the metabolic syndrome at age 43 years in the unadjusted model $(\mathrm{OR}=2 \cdot 25 ; 95 \% \mathrm{CI} 1 \cdot 43$, 3.54; see Table 2). The association was only marginally

Table 1 Descriptive statistics for 889 participants from the Northern Swedish Cohort, according to breakfast habits

\begin{tabular}{|c|c|c|c|c|c|c|c|}
\hline & \multicolumn{3}{|c|}{ Eating breakfast at age 16 years } & \multicolumn{3}{|c|}{ Poor breakfast habits at age 16 years } & \multirow[b]{2}{*}{$P$ value } \\
\hline & $n$ & $\%$ or Median & IQR & $n$ & $\%$ or Median & IQR & \\
\hline \multicolumn{8}{|l|}{ Variables at age 16 years } \\
\hline Male (\%) & 801 & $51 \cdot 2$ & & 88 & $61 \cdot 4$ & & 0.073 \\
\hline Low parental SES (\%) & 797 & $38 \cdot 1$ & & 87 & $40 \cdot 2$ & & 0.728 \\
\hline Family history of diabetes (\%) & 795 & 3.52 & & 88 & $9 \cdot 09$ & & 0.021 \\
\hline $\mathrm{BMI}\left(\mathrm{kg} / \mathrm{m}^{2}\right)$ & 801 & $19 \cdot 5$ & $3 \cdot 13$ & 88 & $20 \cdot 0$ & $2 \cdot 90$ & 0.099 \\
\hline Daily intake of sweets and pastries (\%) & 799 & $15 \cdot 9$ & & 88 & $19 \cdot 3$ & & 0.446 \\
\hline High alcohol intake (\%) & 797 & $18 \cdot 1$ & & 86 & $37 \cdot 2$ & & $<0.001$ \\
\hline Smoking (\%) & 799 & $22 \cdot 9$ & & 88 & $52 \cdot \overline{3}$ & & $<0.001$ \\
\hline Exercise more than once weekly (\%) & 801 & $50 \cdot 8$ & & 88 & $23 \cdot 9$ & & $<0.001$ \\
\hline \multicolumn{8}{|l|}{ Variables at age 43 years } \\
\hline Metabolic syndrome (\%) & 801 & $25 \cdot 2$ & & 88 & $43 \cdot 2$ & & 0.001 \\
\hline Central obesity (\%) & 797 & $58 \cdot 0$ & & 88 & $75 \cdot 0$ & & 0.002 \\
\hline High TAG (\%) & 798 & $22 \cdot 9$ & & 86 & $37 \cdot 2$ & & 0.005 \\
\hline Low HDL-cholesterol (\%) & 798 & $28 \cdot 1$ & & 86 & $36 \cdot 0$ & & $0 \cdot 133$ \\
\hline High blood pressure (\%) & 801 & $39 \cdot 8$ & & 88 & $52 \cdot 3$ & & 0.030 \\
\hline High fasting glucose (\%) & 796 & $16 \cdot 2$ & & 88 & $30 \cdot 7$ & & 0.002 \\
\hline
\end{tabular}

IQR, interquartile range; SES, socio-economic status.

Table 2 Logistic regression analyses of associations between poor breakfast habits at age 16 years and the metabolic syndrome at age 43 years, for 889 participants from the Northern Swedish Cohort

\begin{tabular}{|c|c|c|c|c|c|c|c|c|c|}
\hline & \multirow[b]{2}{*}{$n$} & \multicolumn{2}{|c|}{ Unadjusted } & \multicolumn{2}{|c|}{ Model $1^{*}$} & \multicolumn{2}{|c|}{ Model $2 \dagger$} & \multicolumn{2}{|c|}{ Model 3ł } \\
\hline & & OR & $95 \% \mathrm{Cl}$ & OR & $95 \% \mathrm{Cl}$ & OR & $95 \% \mathrm{Cl}$ & OR & $95 \% \mathrm{Cl}$ \\
\hline Eating breakfast & 801 & $1 \cdot 00$ & & $1 \cdot 00$ & & $1 \cdot 00$ & & 1.00 & \\
\hline $\begin{array}{l}\text { Poor breakfast habits } \\
\text { Covariates }\end{array}$ & 88 & $2 \cdot 25$ & $1 \cdot 43,3 \cdot 54$ & $2 \cdot 14$ & $1 \cdot 35,3 \cdot 39$ & $1 \cdot 71$ & $1 \cdot 05,2 \cdot 78$ & 1.68 & $1 \cdot 01,2 \cdot 7 \varepsilon$ \\
\hline Sex (male) & 889 & & & $2 \cdot 11$ & $1 \cdot 55,2 \cdot 89$ & $2 \cdot 28$ & $1 \cdot 64,3 \cdot 15$ & $2 \cdot 47$ & $1 \cdot 76,3 \cdot 46$ \\
\hline Family history of diabetes & 883 & & & & & $2 \cdot 25$ & $1 \cdot 10,4 \cdot 60$ & $2 \cdot 15$ & $1 \cdot 02,4 \cdot 4 \mathrm{C}$ \\
\hline High alcohol consumption & 883 & & & & & 1.09 & $0.71,1.67$ & 0.96 & $0.61,1.49$ \\
\hline Smoking & 887 & & & & & $1 \cdot 16$ & $0 \cdot 77,1 \cdot 76$ & $1 \cdot 23$ & $0 \cdot 80,1 \cdot 89$ \\
\hline Physically active & 889 & & & & & 0.68 & $0.49,0.95$ & 0.65 & $0.46,0.92$ \\
\hline $\mathrm{BMl}\left(\mathrm{kg} / \mathrm{m}^{2}\right)$ & 889 & & & & & & & $1 \cdot 20$ & $1 \cdot 12,1 \cdot 27$ \\
\hline Low parental SES & 884 & & & & & & & $1 \cdot 22$ & $0.88,1.69$ \\
\hline
\end{tabular}

SES, socio-economic status

${ }^{*}$ Adjusted for sex.

tModel 1 plus family history of diabetes, high alcohol consumption, smoking and physical activity (variables associated with the metabolic syndrome $(P<0 \cdot 25)$ and significantly different between breakfast groups) at age 16 years.

‡Model 2 plus BMI and parents' SES. 
Table 3 Logistic regression analyses of associations between breakfast skipping at age 16 years and components of the metabolic syndrome at age 43 years, for 889 participants from the Northern Swedish Cohort

\begin{tabular}{|c|c|c|c|c|c|c|c|c|c|c|}
\hline & \multicolumn{2}{|c|}{ Central obesity* } & \multicolumn{2}{|c|}{ High TAG* } & \multicolumn{2}{|c|}{ Low HDL-cholesterol* } & \multicolumn{2}{|c|}{ High blood pressure* } & \multicolumn{2}{|c|}{ High fasting glucose } \\
\hline & OR & $95 \% \mathrm{Cl}$ & OR & $95 \% \mathrm{Cl}$ & OR & $95 \% \mathrm{Cl}$ & OR & $95 \% \mathrm{Cl}$ & OR & $95 \% \mathrm{Cl}$ \\
\hline Eating breakfast & $1 \cdot 00$ & & $1 \cdot 00$ & & $1 \cdot 00$ & & $1 \cdot 00$ & & $1 \cdot 00$ & \\
\hline Poor breakfast habits & $2 \cdot 18$ & $1 \cdot 31,3 \cdot 60$ & 1.99 & $1 \cdot 24,3 \cdot 18$ & $1 \cdot 44$ & $0 \cdot 90,2 \cdot 31$ & $1 \cdot 66$ & $1 \cdot 06,2 \cdot 58$ & $2 \cdot 29$ & $1 \cdot 40,3 \cdot 74$ \\
\hline Model 1† & $2 \cdot 20$ & $1 \cdot 32,3 \cdot 64$ & $1 \cdot 83$ & $1 \cdot 11,2.99$ & $1 \cdot 45$ & $0.90,2.31$ & 1.54 & $0.98,2.43$ & $2 \cdot 14$ & $1 \cdot 29,3 \cdot 54$ \\
\hline Model $2 \ddagger$ & $1 \cdot 85$ & $1 \cdot 10,3 \cdot 12$ & $1 \cdot 51$ & $0 \cdot 89,2 \cdot 53$ & $1 \cdot 24$ & $0 \cdot 75,2 \cdot 04$ & $1 \cdot 25$ & $0 \cdot 77,2 \cdot 02$ & $1 \cdot 79$ & $1 \cdot 05,3 \cdot 05$ \\
\hline Model $3 \S$ & $1 \cdot 71$ & $1.00,2.92$ & $1 \cdot 48$ & $0.86,2.53$ & $1 \cdot 25$ & $0.76,2 \cdot 07$ & $1 \cdot 17$ & $0.71,1.91$ & $1 \cdot 75$ & $1.01,3.02$ \\
\hline
\end{tabular}

${ }^{*}$ Definition according to the International Diabetes Federation Guidelines ${ }^{(25)}$.

†Adjusted for sex.

¥Model 1 plus family history of diabetes, high alcohol consumption, smoking and physical activity.

$\S$ Model 2 plus BMI and parents' socio-economic status.

attenuated by the addition of sex (model 1) and moderately attenuated by the addition of selected covariates (model 2: family history of diabetes, alcohol consumption, smoking status and physical activity at age 16 years). After further adjustments for SES and BMI at age 16 years, there was an insubstantial change of odds ratio, with the odds for poor breakfast habits remaining significant (model 3: OR $=1 \cdot 68 ; 95 \%$ CI 1.01, 2.78; Table 2). Covariates significantly related to the metabolic syndrome in model 3 were sex, family history of diabetes, physical activity and BMI at age 16 years (Table 2).

In separate analyses of components of the metabolic syndrome (Table 3), central obesity and high fasting glucose at age 43 years were associated with poor breakfast habits at age 16 years in all models. For TAG at age 43 years, the association with poor breakfast habits at age 16 years was significant in the crude model and model 1 but not in subsequent models. The association between poor breakfast habits at age 16 years and high blood pressure at age 43 years was significant only in the crude model, whereas the association with HDL-cholesterol at age 43 years was not significant in any of the models.

Adding consumption of fruits and vegetables as well as physical activity at age 43 years to the multivariate model attenuated the association between poor breakfast habits at age 16 years and risk of the metabolic syndrome at age 43 years, and it was no longer statistically significant $(\mathrm{OR}=1 \cdot 53 ; 95 \%$ CI $0 \cdot 91,2 \cdot 57)$.

\section{Discussion}

In the present study with high participation rate and low loss to follow-up, poor breakfast habits in adolescence predicted the metabolic syndrome at age 43 years, also after adjustment for potential confounders (such as lifestyle variables and socio-economic conditions) in youth. Of the components of the metabolic syndrome, central obesity and high fasting glucose remained associated with poor breakfast habits also after multivariate adjustments.
Eating breakfast has been associated with an overall better diet quality and healthy lifestyle in several studies ${ }^{(8,10,11)}$. It may therefore be argued that poor breakfast habits predict cardiometabolic risk because it is part of an unhealthy lifestyle. Our finding that those with poor breakfast habits exercise less, drink more alcohol and smoke more than breakfast eaters supports the view that poor breakfast habits is part of an unhealthy lifestyle (Table 1). The finding that poor breakfast habits at age 16 years predicted the metabolic syndrome at age 43 years remained statistically significant after multivariate adjustments with lifestyle variables at age 16 years (smoking, high alcohol consumption, physical activity). This indicates that the association between poor breakfast habits and future metabolic syndrome does not just reflect a covariance between poor breakfast habits and other unhealthy lifestyle habits in adolescence, but that poor breakfast habits have an independent ability to predict metabolic risk. Furthermore, the observation that the association was independent of BMI and SES in adolescence suggests that the association is not simply explained by pre-existing metabolic and social risk factors, which we have previously shown to be related to adult metabolic syndrome ${ }^{(23)}$.

It has been previously found that eating breakfast is associated with a better total diet quality ${ }^{(8)}$ and also with physical activity ${ }^{(30)}$. When we added consumption of fruits and vegetables and physical activity at age 43 years to our multivariate model, the association between poor breakfast habits at age 16 years and the metabolic syndrome at age 43 years was somewhat attenuated and no longer statistically significant. This may be interpreted as if the association, at least to some extent, is mediated by future healthy diet and/or high physical activity level. However, because breakfast habits are often established at an early age ${ }^{(31)}$, the association may also be mediated by breakfast habits at age 43 years. We were unable to examine to what degree the reported association relates to stable breakfast habits over the life course, because we did not have information about breakfast habits at age 43 years. The contribution of the present paper is the observation that early-life breakfast habits predict the 
metabolic syndrome decades later. Further research is needed in order to get a deeper understanding of how adolescent breakfast habits are related to adult metabolic syndrome, including analyses of possible mediating mechanisms.

In our study, central obesity and high fasting glucose at age 43 years were the components of the metabolic syndrome which were most strongly predicted by poor breakfast habits in adolescence. HDL-cholesterol, TAG and high blood pressure were not significantly associated with poor breakfast habits after multivariate adjustments. The stronger associations found for central obesity and high fasting glucose are supported by experimental studies. In the short-term randomized crossover trial by Farshchi et al. ${ }^{(13)}$, breakfast skipping was associated with high fasting insulin. High fasting insulin may contribute to central obesity ${ }^{(32)}$. An experimental study by Pereira et al. suggests that breakfast skipping, as well as breakfast quality, may have important effects on factors related to appetite control and glycaemic control ${ }^{(20)}$. Also, findings in recent observational studies of an association between breakfast omitting and increased risk of type 2 diabetes support an effect on weight and insulin resistance ${ }^{(15,16)}$. These previous findings are in line with our finding that central obesity and fasting glucose are the components of the metabolic syndrome with the strongest associations to poor breakfast habits at age 16 years.

In previous research on breakfast habits and cardiometabolic outcomes, skipping breakfast has been the most common way to define the breakfast exposure. However, even the definition of skipping breakfast has not been completely consistent, as some studies included those only drinking as breakfast skippers ${ }^{(21)}$, while others did not ${ }^{(33,34)}$. When those skipping breakfast and those only drinking or eating something sweet for breakfast at age 16 years were considered in separate categories in our study, the crude odds ratios for the metabolic syndrome at age 43 years were similar for the sub-categories. This justifies combining these into the category 'poor breakfast habits'. Our study does not have power to allow for conclusions concerning skipping breakfast (with the definition of not eating or drinking anything energy-containing at all for breakfast) and the metabolic syndrome. Skipping breakfast or only drinking or eating something sweet for breakfast are different variants of absence of healthy breakfast habits. As stated by Eilat-Adar et $a l^{(35)}$, there is a need for an exact definition of what a healthy breakfast is. Several previous studies have found an especially beneficial effect of ready-to-eat cereals on cardiometabolic risk factors and total nutrient intake ${ }^{(33,36)}$. In our study we did not aim to investigate the influence of breakfast quality, except separating those with distinctively poor breakfast habits. Larger studies are warranted to analyse the relationships between breakfast quality and the metabolic syndrome further.

\section{Metbod discussion}

The prevalence of the metabolic syndrome in the present study $(34.1 \%$ in men and $19.3 \%$ in women) was higher compared with a population-based cohort in another part of Sweden ${ }^{(37)}$. Therefore, the generalizability of our findings to populations with lower prevalence of the metabolic syndrome is unclear.

A limitation of the study is that the definition of breakfast habits at age 16 years was based on one single-day assessment, which would be expected to decrease the measurement precision. However, imprecision of the exposure would lead to dilution and underestimation, rather than overestimation ${ }^{(38)}$, of the association between poor breakfast habits and the metabolic syndrome.

Some further limitations of the study need to be discussed. Although we were able to adjust for physical activity, alcohol consumption and smoking at age 16 years, we could not adjust thoroughly for adolescent dietary habits. Consumption of sweets and pastries at age 16 years did not differ between the breakfast groups (Table 1), but we did not have information on beneficial dietary habits such as fruit and vegetable consumption at age 16 years. Eating a healthy breakfast may aid in sticking to good dietary habits during the rest of the day, by balancing postprandial blood sugar and keeping a balanced energy intake ${ }^{(9,13)}$. As previously mentioned, we did not have information on breakfast habits in adulthood. However, even if the association between breakfast eating in adolescence and lower prevalence of the metabolic syndrome in adulthood were completely due to strong correlation between breakfast habits in adolescence and adulthood and/or to assistance in sticking to healthy dietary habits during the rest of the day, these factors should rather be considered as mediators than confounders.

The main strengths of the current study were the prospective design with long follow-up. The high participation rate and low attrition rate resulted in a very good representativeness. The variables were derived from wellknown and validated questionnaires ${ }^{(22,39,40)}$. In addition, a reliability test of the alcohol and tobacco questions was made in 1981, which showed good 2-month test-retest reliability $^{(27-29)}$.

Considering the amount of people skipping breakfast in the USA and Europe ${ }^{(18)}$, it is crucial from a public health point of view to identify predictors and in future research also analyse possible causal mechanisms behind adolescent breakfast habits and future metabolic risk. Recent data from northern Sweden demonstrated that the prevalence of skipping breakfast in adolescence has increased since the early $1980 \mathrm{~s}^{(19)}$. Offering breakfast in schools, in so-called School Breakfast Programmes, has been shown to have beneficial effects on academic performance $^{(41)}$, but the implications for metabolic health are unclear. 


\section{Conclusions}

Poor breakfast habits at age 16 years predicted the metabolic syndrome at age 43 years, independently of early confounders (lifestyle, BMI and SES). Of the metabolic syndrome components, poor breakfast habits at age 16 years predicted central obesity and high fasting glucose at age 43 years. Based on our findings, we suggest that School Breakfast Programmes should be evaluated regarding metabolic health consequences. Further research is needed to understand how the relationship between early breakfast habits and adult metabolic syndrome is mediated.

\section{Acknowledgements}

Sources of funding: The work was supported through a regional agreement between Umeå University and Västerbotten County Council on cooperation in the field of Medicine, Odontology and Health (ALF). The funding source (ALF) had no role in the design, analysis or writing of this article. Conflicts of interest: The authors have no conflicts of interest to report. Autbors' contributions: A.H. designed the research; A.H. conducted the research (data collection); M.W. analysed the data; M.W., P.E.G., P.W. and A.H. interpreted the data; M.W. wrote the paper; P.E.G., P.W. and A.H. critically revised the paper for important intellectual content; M.W. has primary responsibility for the final content. All authors read and approved the final manuscript.

\section{References}

1. Isomaa B, Almgren P, Tuomi T et al. (2001) Cardiovascular morbidity and mortality associated with the metabolic syndrome. Diabetes Care 24, 683-689.

2. Eckel RH, Grundy SM \& Zimmet PZ (2005) The metabolic syndrome. Lancet 365, 1415-1428.

3. Esmaillzadeh A, Kimiagar M, Mehrabi Y et al. (2006) Fruit and vegetable intakes, C-reactive protein, and the metabolic syndrome. Am J Clin Nutr 84, 1489-1497.

4. Pereira MA, Jacobs DR Jr, Van Horn L et al. (2002) Dairy consumption, obesity, and the insulin resistance syndrome in young adults: the CARDIA Study. JAMA 287, 2081-2089.

5. Sahyoun NR, Jacques PF, Zhang XL et al. (2006) Wholegrain intake is inversely associated with the metabolic syndrome and mortality in older adults. Am J Clin Nutr $\mathbf{8 3}$, 124-131.

6. Dhingra R, Sullivan L, Jacques PF et al. (2007) Soft drink consumption and risk of developing cardiometabolic risk factors and the metabolic syndrome in middle-aged adults in the community. Circulation 116, 480-488.

7. Lutsey PL, Steffen LM \& Stevens J (2008) Dietary intake and the development of the metabolic syndrome: the Atherosclerosis Risk in Communities study. Circulation 117, 754-761.

8. Ruxton CH \& Kirk TR (1997) Breakfast: a review of associations with measures of dietary intake, physiology and biochemistry. Br J Nutr 78, 199-213.

9. de Castro JM (2004) The time of day of food intake influences overall intake in humans. J Nutr 134, 104-111.
10. Song WO, Chun OK, Obayashi S et al. (2005) Is consumption of breakfast associated with body mass index in US adults? J Am Diet Assoc 105, 1373-1382.

11. van der Heijden AA, Hu FB, Rimm EB et al. (2007) A prospective study of breakfast consumption and weight gain among US men. Obesity (Silver Spring) 15, 2463-2469.

12. Timlin MT, Pereira MA, Story M et al. (2008) Breakfast eating and weight change in a 5-year prospective analysis of adolescents: Project EAT (Eating Among Teens). Pediatrics 121, e638-e645.

13. Farshchi HR, Taylor MA \& Macdonald IA (2005) Deleterious effects of omitting breakfast on insulin sensitivity and fasting lipid profiles in healthy lean women. Am J Clin Nutr 81, 388-396.

14. Cahill LE, Chiuve SE, Mekary RA et al. (2013) Prospective study of breakfast eating and incident coronary heart disease in a cohort of male US health professionals. Circulation 128, 337-343.

15. Mekary RA, Giovannucci E, Willett WC et al. (2012) Eating patterns and type 2 diabetes risk in men: breakfast omission, eating frequency, and snacking. Am J Clin Nutr 95, 1182-1189.

16. Mekary RA, Giovannucci E, Cahill L et al. (2013) Eating patterns and type 2 diabetes risk in older women: breakfast consumption and eating frequency. Am J Clin Nutr 98, 436-443.

17. Odegaard AO, Jacobs DR Jr, Steffen LM et al. (2013) Breakfast frequency and development of metabolic risk. Diabetes Care 36, 3100-3106.

18. Rampersaud GC, Pereira MA, Girard BL et al. (2005) Breakfast habits, nutritional status, body weight, and academic performance in children and adolescents. $J \mathrm{Am}$ Diet Assoc 105, 743-760.

19. Vaezghasemi M, Lindkvist M, Ivarsson A et al. (2012) Overweight and lifestyle among 13-15 year olds: a cross-sectional study in northern Sweden. Scand J Public Health 40, 221-228.

20. Pereira MA, Erickson E, McKee P et al. (2011) Breakfast frequency and quality may affect glycemia and appetite in adults and children. J Nutr 141, 163-168.

21. Smith KJ, Gall SL, McNaughton SA et al. (2010) Skipping breakfast: longitudinal associations with cardiometabolic risk factors in the Childhood Determinants of Adult Health Study. Am J Clin Nutr 92, 1316-1325.

22. Hammarström A \& Janlert U (2011) Cohort profile: the northern Swedish cohort. Int J Epidemiol 41, 1545-1552.

23. Gustafsson PE, Persson M \& Hammarström A (2011) Life course origins of the metabolic syndrome in middle-aged women and men: the role of socioeconomic status and metabolic risk factors in adolescence and early adulthood. Ann Epidemiol 21, 103-110.

24. Gustafsson PE, Persson M \& Hammarström A (2012) Socioeconomic disadvantage and body mass over the life course in women and men: results from the Northern Swedish Cohort. Eur J Public Health 22, 322-327.

25. Alberti KG, Zimmet P \& Shaw J (2005) The metabolic syndrome - a new worldwide definition. Lancet 366, 1059-1062.

26. Gustafsson PE \& Hammarström A (2012) Socioeconomic disadvantage in adolescent women and metabolic syndrome in mid-adulthood: an examination of pathways of embodiment in the Northern Swedish Cohort. Soc Sci Med 74, 1630-1638.

27. Hammarström A (1986) Youth unemployment and ill-health: results from a two year follow-up study. Doctoral Thesis, Karolinska Institute (in Swedish with an English summary).

28. Janlert U \& Hammarström A (1992) Alcohol consumption among unemployed youths: results from a prospective study. Br J Addict 87, 703-714.

29. Hammarström A \& Janlert U (1994) Unemployment and change of tobacco habits: a study of young people from 16 to 21 years of age. Addiction 89, 1691-1696. 
30. Schembre SM, Wen CK, Davis JN et al. (2013) Eating breakfast more frequently is cross-sectionally associated with greater physical activity and lower levels of adiposity in overweight Latina and African American girls. Am J Clin Nutr 98, 275-281.

31. Merten MJ, Williams AL \& Shriver LH (2009) Breakfast consumption in adolescence and young adulthood: parental presence, community context, and obesity. $J \mathrm{Am}$ Diet Assoc 109, 1384-1391.

32. Labayen I, Ruiz JR, Ortega FB et al. (2011) Insulin sensitivity at childhood predicts changes in total and central adiposity over a 6-year period. Int J Obes (Lond) 35, 1284-1288.

33. Deshmukh-Taskar P, Nicklas TA, Radcliffe JD et al. (2013) The relationship of breakfast skipping and type of breakfast consumed with overweight/obesity, abdominal obesity, other cardiometabolic risk factors and the metabolic syndrome in young adults. The National Health and Nutrition Examination Survey (NHANES): 1999-2006. Public Health Nutr 16, 2073-2082.

34. Min C, Noh H, Kang YS et al. (2011) Skipping breakfast is associated with diet quality and metabolic syndrome risk factors of adults. Nutr Res Pract 5, 455-463.
35. Eilat-Adar S, Koren-Morag N, Siman-Tov M et al. (2011) School-based intervention to promote eating daily and healthy breakfast: a survey and a case-control study. Eur J Clin Nutr 65, 203-209.

36. Affenito SG, Thompson D, Dorazio A et al. (2013) Readyto-eat cereal consumption and the school breakfast program: relationship to nutrient intake and weight. $J$ Sch Health 83, 28-35.

37. Welin L, Adlerberth A, Caidahl K et al. (2008) Prevalence of cardiovascular risk factors and the metabolic syndrome in middle-aged men and women in Gothenburg, Sweden. BMC Public Health 8, 403.

38. Carroll R (1998) Measurement error in epidemiologic studies. In Encyclopedia of Biostatistics, pp. 2491-2519 [P Armitage and T Colton, editors]. Chichester: Wiley.

39. Hibell B \& Jonsson E (1981) Undersökning om skolungdomens alkobol-, narkotika-, tobaks- och sniffningsvanor våren 1980. Stockholm: Skolöverstyrelsen.

40. Kannas L \& Hietaharju M (1980) Unga arbetslösa mäns hälsobeteende. Socialmedicinsk tidskrift 57, 170-176.

41. Hoyland A, Dye L \& Lawton CL (2009) A systematic review of the effect of breakfast on the cognitive performance of children and adolescents. Nutr Res Rev 22, 220-243. 